Article

\title{
Effect of Nano Alumina on the Properties of Fluorinated Polyurethane
}

\author{
Ruizhu Zhang ${ }^{1}$, Wenbo Wang ${ }^{1, *}$, Chongyang Wang ${ }^{1}$, Wejie Tian ${ }^{1}$, Jianlin Hang ${ }^{2}$ \\ and M. Irfan Hussain ${ }^{3}$ \\ 1 School of Mechanical Engineering, North China University of Water Resources and Electric Power, \\ Zhengzhou 450045, China; zhangruizhu@ncwu.edu.cn (R.Z.); wcy199436@163.com (C.W.); \\ tian102623@163.com (W.T.) \\ 2 Henan Tianma New Material Co., Ltd., Zhengzhou 450025, China; zztmwfgs158@sina.com \\ 3 School of Materials Science and Engineering, University of Science and Technology Beijing, Beijing 100083, \\ China; h.irfan.uaf@Outlook.com \\ * Correspondence: z201710415269@stu.ncwu.edu.cn; Tel.: +86-132-5367-9690
}

Received: 30 October 2019; Accepted: 5 December 2019; Published: 9 December 2019

\begin{abstract}
This article selects studies on the preparation of fluorinated polyurethane-nano-alumina composite coating materials, and analyzes the anti-wear, water resistantance, and surface microstructure. Attenuated total reflection-Fourier transform infrared spectroscopy (ATR-FTIR) shows that the polyurethane synthesized in this study does not contain hydrophilic $-\mathrm{CH}_{2} \mathrm{OH}$ groups. The cavitation wear test depicts that the actual cavitation amount $\mathrm{C}$ of the $\mathrm{Al}_{2} \mathrm{O}_{3}$-FPU (4) (fluorinated polyurethane) coating is $0.9035 \times 10^{-3} \mathrm{~kg}$, and the anti-wear ability increases by $61.9 \%$ compared with FPU-0.5. The water-resistant test shows that the contact angle of water droplets on the surface of the coating increase from $95.3^{\circ}$ of FPU-0.5 to $123.1^{\circ}$ of $\mathrm{Al}_{2} \mathrm{O}_{3}$-FPU (4), and the water absorption decreases from $2.52 \%$ to $1.04 \%$. Scanning electron microscopy (SEM) observation confirms that alumina particles can protrude on the coating surface and resist strong wear, while the C-F chain with high bond energy at the near-surface exhibits high strength and water resistance, which prevents wear from spreading deep into the coating. Differential scanning calorimetry (DSC) results show that the $\mathrm{Tg}_{(\mathrm{HS})}$ value of the hard segment phase decreases with higher external force. Notably, when the coating is subjected to erosion, which enhances the crystallinity of the hard segment phase, the tensile strength of the hard segment phase of the coating surface is improved, which supports the wear resistance. Herein, we show that the addition of nano-alumina to fluorinated polyurethanes can control high water and abrasion resistance.
\end{abstract}

Keywords: fluorinated polyurethane; nano-alumina; coating; water resistant; anti-wear

\section{Introduction}

Surface damage and destruction caused by cavitation wear have always been a great challenge during operating and maintenance management of hydraulic engineering [1]. Yet, most wear-resistant and anti-corrosive coatings contain organic volatiles that are extremely harmful to the environment and water resources. Besides, ordinary epoxy coatings are not suitable for applications with impact protection and elastic expansion because they are too hard and insufficiently flexibility. Polyurethane is a polymer material with excellent physical properties, namely, high elasticity, high tear resistance, wear resistance, and anti-corrosion [2-4]. Even though there has been continuous development and improvement of polyurethane, its application range still faces some serious challenges and needs to be made more extensive. However, due to its good anti-fatigue, cavitation resistance, and high- and low-temperature toughness, it plays an important role in the anti-wear protection 
of underwater concrete and hydraulic engineering steel structures [5-7]. Shuang Xiao et al. [8] studied the effect of molecular weight on the scratch and abrasive wear behavior of three model thermoplastic polyurethane (TPU) elastomers. Studies have found that increasing the molecular weight can increase the tensile strength of TPU samples. Higher molecular weights have enhanced resistance to cracking and scratching. However, the limitations are also great in some respects $[9,10]$. For example, polyurethane is usually obtained by reacting diisocyanates or polyisocyanates with alcohols and has poor water resistance due to the presence of a hydrophilic group $-\mathrm{CH}_{2} \mathrm{OH}$ on the molecular chain of the polyurethane [11,12]. The introduction of hydrophobic structure and crosslinked structure into the molecular chain of polyurethane is the main approach to solve the underwater performance of polyurethane. The fluorine segment and silicon segment are the main constitutuents of two hydrophobic structures introduced at this stage [13]. Zhihau Li et al. [14] successfully prepared fluorosilicone polyurethane. The results showed that when the amount of hydroxyl fluorosilicone oil was $40 \mathrm{wt} \%$, compared with polyurethane, the water contact angle of fluorosulfur polyurethane (FSPU) increased to $113.6^{\circ}$, the water absorption rate decreased to $0.7 \%$, and the hydrophobic property was significantly improved. Yi Zhou et al. [15] prepared hydrophobic fluorosilicone polyacrylate polyurethane coating and clarified the surface self-segregation characteristics of the fluorine segment and the silicon segment. The coating showed excellent surface hydrophobicity with amphoteric points, strong thermal stability, and controllable mechanical properties. Lei Chen et al. [16] prepared the triblock copolymer series with a polyurethane (PU) middle block and fluorinated end blocks, poly 2,2,2-trifluoroethyl methacrylate (PTFEMA). Static contact angle tests demonstrate that the triblock copolymer with PTFEMA of 0.03 already attained a much higher value of the water contact angle $\left(95^{\circ}\right)$ than the value $\left(74^{\circ}\right)$ of the PU homopolymer. It has been demonstrated that the addition of very low levels of nanomaterials can provide excellent composite properties to the polyurethane coatings [17-20]. To improve the wear resistance of polyurethane elastomer under erosive conditions, R. Zhou et al. [21] studied the effect of $\mathrm{Al}_{2} \mathrm{O}_{3}$ content and different silane coupling agents on mechanical properties and erosion wear properties, and prepared polyurethane matrix composites. The results show that with the increase of $\mathrm{Al}_{2} \mathrm{O}_{3}$ particle content, the wear resistance of the composite increases first and then decreases, and the erosion wear mechanism of the composite was discussed. Zhang Min and Chen Yufei et al. [22,23] added nano-alumina material to the polyurethane, and the coating improved corrosion resistance, wear resistance, and thermal stability. There is little research on the preparation of composite coatings by adding nano alumina to fluorinated polyurethane. The synthesis of composite polyurethane coatings with both anti-corrosion, abrasion resistance, and water resistance is a serious problem that needs to be solved today. In this paper, we introduced fluorinated polyurethane-alumina composite coating, which was prepared by grafting an organofluoroalkyl group in a polyurethane segment and adding nano-alumina, which significantly improved the water resistance and wear resistance of the coating.

\section{Materials and Methods}

\subsection{Materials}

Diphenyl-methane-diisocyanate (MDI) was purchased from Sigma-Aldrich, and was industrially pure. Polytetrahydrofuran ether glycol (PTMEG) was purchased from Shanghai kuang chemical material co. LTD (Shanghai, China), molecular weight 1000, vacuum dehydration at $70{ }^{\circ} \mathrm{C}$ for $3 \mathrm{~h}$ before being used. Perfluorooctyl alcohol (TEOH-8) was provided by Hengtong fluorine chemical co. LTD (Fuxin, China), and had chemical purity of $97 \%$ (GC\&T) (Gas chromatography and Techincal grade). Triethylene glycol (TEG) was purchased from Sigma-Aldrich, and had chemically purity of $99 \%$ (GC\&T). Nano-alumina (mean particle diameter $=70.5 \mathrm{~nm}$, specific surface area $=195.59 \mathrm{~m}^{2} \cdot \mathrm{g}^{-1}$ ) was provided by Zhengzhou Tianma new material co. LTD (Zhengzhou, China). KH-550 was purchased from Hubei huaxin organic silicon new material co. LTD (Hubei, China), and was chemically pure. The solvents used in the experiments were $\mathrm{N}, \mathrm{N}$-dimethylformamide (DMF), N,N-dimethylacetamide (DMAC), 
tetrahydrofuran (THF), methyl ethyl ketone, acetic acid, acetone, and methanol. The above solvents were purchased from Shanghai han photochemical reagent co. LTD (Shanghai, China), and they were all chemically pure.

\subsection{Experiments Methods}

\subsubsection{Surface Modification of Nano Alumina}

The silane coupling agent $\mathrm{KH}-550$ was dissolved in an ethanol solution, and the $\mathrm{pH}$ of the reaction mixture was adjusted to 4-5 using acetic acid and stirred at room temperature for $2 \mathrm{~h}$. Then, the nano-alumina and KH-550 were added to the reaction kettle and stirred at $60{ }^{\circ} \mathrm{C}$ for $4 \mathrm{~h}$. KH-550 accounted for $1.5 \%$ of the mass of the nano-alumina. The alumina granules obtained by centrifugation were washed several times with ethanol and then dried for use.

\subsubsection{Preparation of Fluorinated Polyurethane-Nano-Alumina Composite Coating}

The first step involved dissolving MDI in DMF and pouring it into a four-necked flask protected with nitrogen. The remaining three ports of the four-necked flask were equipped with a stirrer, a thermometer, and a constant pressure dropping funnel. Perfluorooctylethyl alcohol was added dropwise to the DMF solution in the flask at $4 \mathrm{~d} / \mathrm{s}$ using a constant pressure dropping funnel. The reaction was continued at $50{ }^{\circ} \mathrm{C}$ for $2.5 \mathrm{~h}$ at a stirring speed of $70 \mathrm{rpm}$. The molar ratio of TEOH-8 to DMF was 1:1 (the molar ratio of TEOH-8/MDI was about 0.5 , and the synthesized polyurethane was referred to as FPU-0.5). The four-necked flask was heated to a temperature of $60^{\circ} \mathrm{C}$, polytetrahydrofuran was added to the reaction system, and the mixture was reacted for $2 \mathrm{~h}$ using a stirrer. A fluoropolyurethane prepolymer with PTMEG as a soft segment was synthesized in this process. In the second step, nano-alumina was dispersed in acetone at room temperature for $2 \mathrm{~h}$ using ultrasonic equipment, which was manufactured by Dongguan taiming CNC machinery co. LTD (Dongguan, China). Additionally, the ultrasonic frequency was set to $50 \mathrm{kHz}$. The dispersed alumina system was added to the pre-polymer, stirred for $2 \mathrm{~h}$ (after being uniformly dissolved), added TEG to the flask, and reacted at $80^{\circ} \mathrm{C}$ for $3 \mathrm{~h}$. In the third step, the temperature was adjusted to $70^{\circ} \mathrm{C}$ for distillation (after the distillate was significantly reduced), the temperature was further increased to $100{ }^{\circ} \mathrm{C}$, and vacuum distillation was performed by a vacuum pump. The mixture was then cooled to room temperature when the bubbles were no longer generated. Finally, the reaction material was poured on pre-treated alloy steel sheets (surface sandblasted roughened, brushed with epoxy two-component primer, and primer cured for $6 \mathrm{~h}$ ) and placed in a constant temperature electric oven at $60^{\circ} \mathrm{C}$ for curing to fully matured. That is, a fluorinated polyurethane-alumina composite coating having a perfluoro segment on one side and a hydrophobic $-\mathrm{COOCH}_{3}$ group on the other end was obtained. FPU synthesis scheme is shown in Figure 1.

Five different alumina content coatings were prepared in this experiment. The mass percentages of alumina were $0 \%, 1 \%, 2 \%, 3 \%$, and $4 \%$, recorded as FPU-0.5, $\mathrm{Al}_{2} \mathrm{O}_{3}$-FPU (1), $\mathrm{Al}_{2} \mathrm{O}_{3}$-FPU (2), $\mathrm{Al}_{2} \mathrm{O}_{3}$-FPU (3), and $\mathrm{Al}_{2} \mathrm{O}_{3}$-FPU (4).

Meanwhile, the experiment was carried out by reacting 1,5-naphthalene diisocyanate(NDI) with Ethylenediamine (EDA) (n(NDI):n(EDA) = 1.25) and NDI with 1,4-butanediol(BDO) $(\mathrm{n}(\mathrm{NDI}) \mathrm{n}(\mathrm{BDO})=1.25)$ to synthesize the compound as reference compounds. 


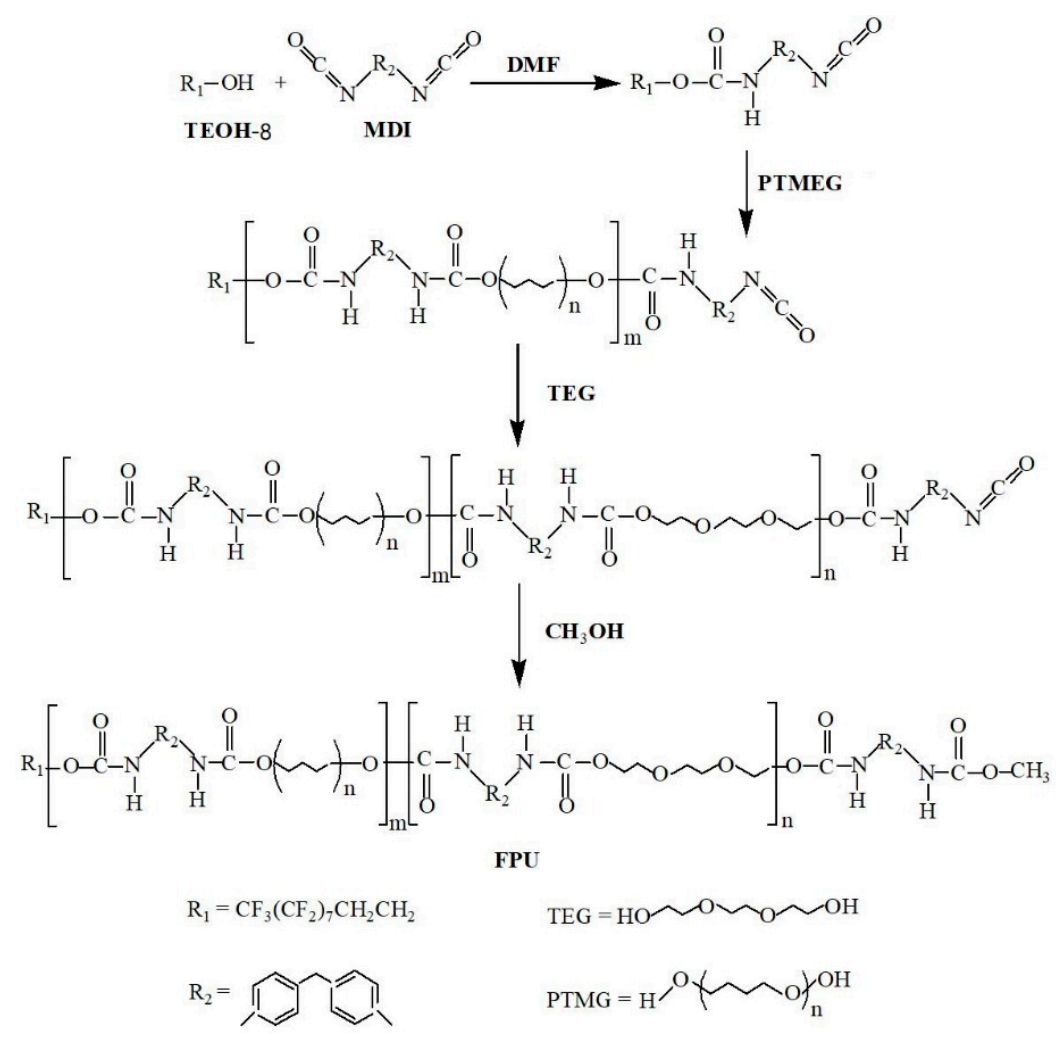

Figure 1. Reaction scheme of FPU (fluorinated polyurethane).

\subsection{Characterizations}

To visualize whether the FPU was synthesized in this experiment, the ATR-FTIR characterization method was used to detect and analyze the polymerization product. The FPU-0.5 was tested by Nicolet is 10 Fourier transform infrared spectrometer. The ATR mode was selected and the scanning precision was set to $4 \mathrm{~cm}^{-1}$. The number of scans was 32 times, and the test range was $400 \mathrm{~cm}^{-1}$ to $4000 \mathrm{~cm}^{-1}$ [24].

COXEM EM-30AX scanning electron microscope (COXEM Co., Ltd. Daejeon, Korea ) was used to examine the samples with different nano alumina content. The surface of the samples was sprayed with a 10-20 $\mathrm{nm}$ gold plating layer by vacuum evaporator [25].

OCA20 video contact angle tester was used for testing (Shanghai Sunzern Instrument Co., Ltd., Shanghai, China). The syringe, dosing tube, and injection needle were thoroughly wetted with deionized water before the experiment, and the syringe was filled with deionized water without any blistering. The water droplets dripped on the surface of the coating for $1 \mathrm{~min}$ before observation, and three test points were taken for each sample and averaged.

EMS-10 magnetic stirring heated water bath was used to test (Shanghai Meiyingpu Instrument Manufacturing Co., Ltd., Shanghai, China). The sample with mass $\mathrm{m}_{1}$ was weighed, and the area of sample $2 / 3$ was immersed in warm water. The water temperature was set at $30^{\circ} \mathrm{C}$, and the magnetic stirring speed was $240 \mathrm{rpm}$. After $200 \mathrm{~h}$, the water was removed from the surface with filter paper and the sample denoted as $\mathrm{m}_{2}$ was weighed. The water absorption of the sample was calculated as follows:

$$
\eta=\left[\left(m_{2}-m_{1}\right) / m_{1}\right] \times 100 \%
$$

The sample with the original mass of $\mathrm{m}_{1}$ was placed in an erosion wear tester, and the wear resistance test was carried out. The sample size was $120 \mathrm{~mm} \times 100 \mathrm{~mm} \times 2 \mathrm{~mm}$, and the mortar was used for the wear test. The quartz sand grain size of the mortar was $0.1-0.4 \mathrm{~mm}$, mortar concentration $30 \%-50 \%$, test line speed was $15 \mathrm{~m} / \mathrm{s}$, and the angle formed $45^{\circ}$. The erosion test lasted $480 \mathrm{~h}$, and the mortar was replaced every $24 \mathrm{~h}$ during the experiment. After the erosion wear test, the sample was 
dried and its mass measured as $\mathrm{m}_{2}$ by an electronic balance with an accuracy of $0.0001 \mathrm{~g}$. In the experiment, the cavitation wear resistance of the material was evaluated by the actual cavitation amount. When the actual cavitation amount $C$ was smaller than the cavitation guarantee amount $C_{n}$ $\left(C \leq C_{n}\right)$ converted according to the actual time, it was regarded as qualified.

According to the actual running time calculation of cavitation erosion quantity, the computation formula is as follows [26]:

$$
\begin{gathered}
\mathrm{C}_{\mathrm{n}}=\mathrm{C}_{\mathrm{r}}\left(\mathrm{t}_{\mathrm{n}} / \mathrm{t}_{\mathrm{r}}\right)^{\mathrm{n}} \\
\mathrm{C}_{\mathrm{r}}=\mathrm{K}_{\mathrm{m}} \mathrm{D}^{2}
\end{gathered}
$$

In which $\mathrm{C}_{\mathrm{r}}$ stands for cavitation guarantee amount, $\mathrm{kg}$; $\mathrm{n}$ is for conversion index, $\mathrm{n}=1.0$; $\mathrm{K}_{\mathrm{m}}$ stands for the quality assurance coefficient, $\mathrm{K}_{\mathrm{m}}=0.8$; $\mathrm{D}$ is for the nominal diameter of sample rotation, $100 \times 10^{-3} \mathrm{~m}$; $t_{\mathrm{n}}$ is for the actual running time, $480 \mathrm{~h}$; and $\mathrm{t}_{\mathrm{r}}$ is for base running time, $8000 \mathrm{~h}$.

In this test, the sample size was $120 \mathrm{~mm} \times 100 \mathrm{~mm} \times 2 \mathrm{~mm}, \mathrm{C}_{\mathrm{r}}=0.8 \times\left(100 \times 10^{-3}\right)^{2}=8 \times 10^{-3} \mathrm{~kg}$. The conditions such as sediment content and impact speed were 5-30 times the actual conditions of hydraulic over-current components, $\mathrm{t}_{\mathrm{n}} \approx 5 \times 480 \mathrm{~h}, \mathrm{n}=1.0$. They were substituted and calculated as follows:

$$
\mathrm{C}_{\mathrm{n}}=8 \times 10^{-3} \times(5 \times 480 \div 8000)^{1}=2.4 \times 10^{-3} \mathrm{~kg} .
$$

The actual cavitation amount is calculated as follows:

$$
\mathrm{C}=\mathrm{m}_{1}-\mathrm{m}_{2}
$$

PosiTest AT pull-off adhesion tester was used to verify the adhesion of the sample before and after the water absorption test and the erosion-resistant test. Three test points were selevted for each sample. The nearest distance between the edge of each two test points was greater than $15 \mathrm{~mm}$, taking the average of the test results.

Mechanical properties were tested at $25{ }^{\circ} \mathrm{C}$ with SANS computer controlled electronic tensile testing machine (Lixian Instrument Technology Co., Ltd., Dongguan, China). Three groups of tensile tests were conducted, with elongation rates of $10 \%, 30 \%$, and $70 \%$, and marked as FPU-0.5(10), FPU-0.5(30), and FPU-0.5(70). The elongated samples were, respectively, fixed on steel sheets and kept for $24 \mathrm{~h}$ to prevent them from rebounding, to perform differential scanning calorimetry analysis.

Differential scanning calorimetry (DSC) was carried out using the TA instrument company Modulated DSC-2910 instrument (Shanghai, China). For the first time, heat from room temperature was raised to $200{ }^{\circ} \mathrm{C}$ and stabilized for 3 mins to eliminate the heat history. Then, it was cooled to $-100{ }^{\circ} \mathrm{C}$ at $20 \mathrm{~K} / \mathrm{min}$ and stabilized for $5 \mathrm{mins}$. The scanning temperature range of the test was $-100-200{ }^{\circ} \mathrm{C}$, and the heating rate was $10 \mathrm{~K} / \mathrm{min}$ under the atmosphere of nitrogen.

\section{Results and Discussion}

\subsection{Analyses of FTIR-ATR}

Fourier infrared absorption spectrum is shown in Figure 2. As in figure, FPU-0.5 has the characteristic peaks $[27,28]$ : the stretching vibration peak of $\mathrm{N}-\mathrm{H}$ appears at $3278 \mathrm{~cm}^{-1}$. The characteristic peak of $2850-2930 \mathrm{~cm}^{-1}$ corresponds to the stretching vibration of the polyether soft segment $-\mathrm{CH}_{3},=\mathrm{CH}_{2}, \equiv \mathrm{CH}$, and the peak of $1727 \mathrm{~cm}^{-1}$ is the stretching vibration of $\mathrm{C}=\mathrm{O} .1597 \mathrm{~cm}^{-1}$ is the benzene ring skeleton vibration. The disappearance of the absorption peaks of $-\mathrm{NCO}\left(2270 \mathrm{~cm}^{-1}\right)$ and $-\mathrm{OH}\left(3340 \mathrm{~cm}^{-1}\right)$ proves the synthesis of FPU. The characteristic peak at $1542 \mathrm{~cm}^{-1}$ is the bending vibration of $\mathrm{N}-\mathrm{H}$ and the stretching vibration of $\mathrm{C}-\mathrm{N}$. At $738.20 \mathrm{~cm}^{-1}, 812.17 \mathrm{~cm}^{-1}$, and $1215.97 \mathrm{~cm}^{-1}$, they are, respectively, $=\mathrm{CF}_{2},-\mathrm{CF}_{3}$, and $-\mathrm{CF}$ stretching vibration absorption peaks, which confirms the existence of fluorine element. According to the above analysis, fluorinated polyurethane without hydrophilic $-\mathrm{CH}_{2} \mathrm{OH}$ group can be obtained using the method adopted in this paper. 


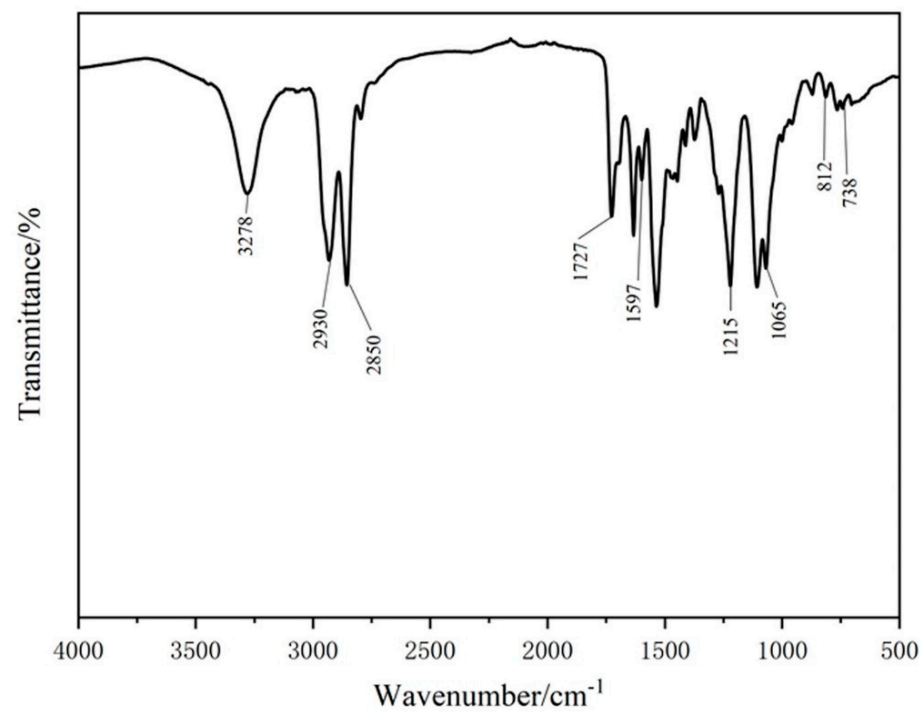

Figure 2. Infrared absorption spectra of FPU-0.5.

\subsection{SEM Analysis}

It can be seen in Figure 3 that as the content of nano-alumina added to the coating material increases, the amount of nano-alumina observed on the surface of the coating increases significantly, while some of the larger structures are due to the agglomeration of the nanoparticles. When the nano-alumina content was $4 \%$, the agglomeration phenomenon drastically increased. When the nano-alumina content was 3\%, the dispersion effect was greatest. The fluorocarbon chain with lower surface energy migrates to the surface layer of the coating to form a micro-nano-scale protrusion structure, and the surface roughness becomes large, thereby enhancing the water resistance of the coating. When the coating was subjected to wear, the alumina on the surface of the coating had large hardness and could withstand most of the friction, thus reducing the rate of wear of the coating. The C-F segment with high bond energy near the surface layer has high strength and water resistance, which prevent wear and continue to penetrate the coating $[29,30]$.

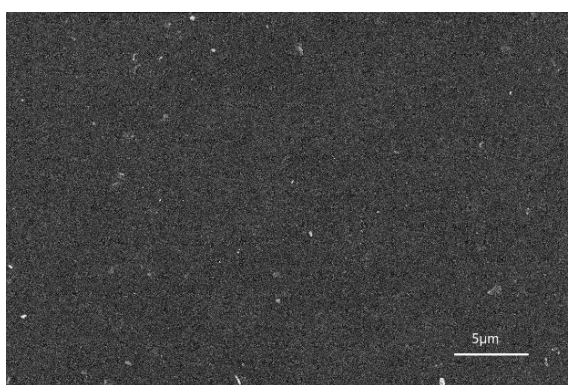

(a)

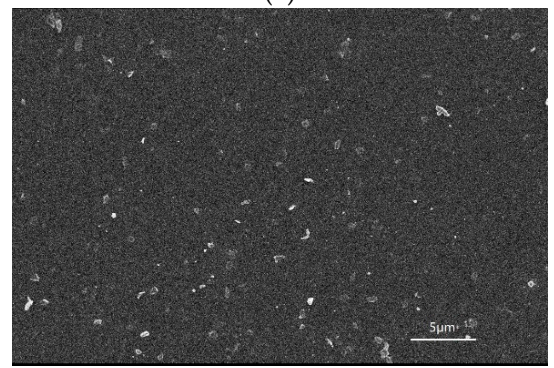

(c)

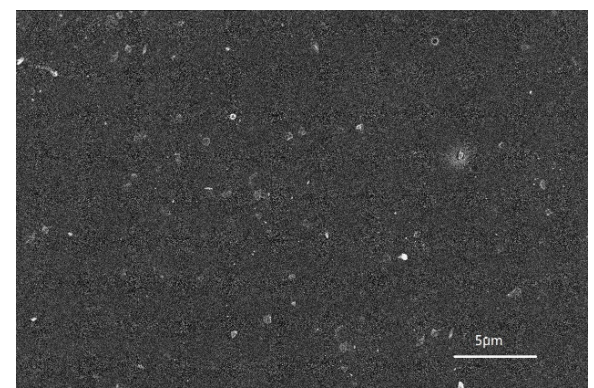

(b)

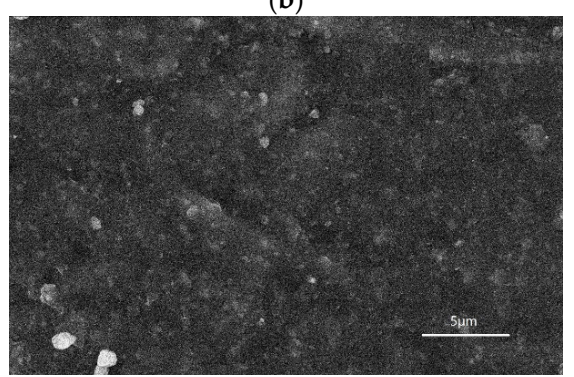

(d)

Figure 3. Surface morphology of coatings with different nano-alumina content: (a) $\mathrm{Al}_{2} \mathrm{O}_{3}-\mathrm{FPU}(1)$, (b) $\mathrm{Al}_{2} \mathrm{O}_{3}-\mathrm{FPU}(2)$, (c) $\mathrm{Al}_{2} \mathrm{O}_{3}-\mathrm{FPU}(3)$, and (d) $\mathrm{Al}_{2} \mathrm{O}_{3}-\mathrm{FPU}(4)$. 


\subsection{Analysis of Water Resistance of Coating}

As the amount of alumina increases, the contact angle of water droplets on the surface of the polyurethane coating increases from $95.3^{\circ}$ of FPU-0.5 to $123.1^{\circ}$ of $\mathrm{Al}_{2} \mathrm{O}_{3}-\mathrm{FPU}(4)$, while the water absorption of the coating in Table 1 was also significantly reduced from $2.52 \%$ to $1.04 \%$. Obviously, the hydrophobic properties of the coating increase with increasing alumina content. It is worth noting that when the alumina content was increased from $3 \%$ to $4 \%$, the water contact angle of the coating increased less, and the water resistance did not change significantly.

Table 1. The data of water resistance experiments.

\begin{tabular}{ccccccc}
\hline Sample & $\begin{array}{c}\text { Contact } \\
\mathbf{A n g l e}^{\circ}\end{array}$ & $\begin{array}{c}\text { Weight, } \\
\mathbf{m}_{\mathbf{1}} \mathbf{/ g}\end{array}$ & $\begin{array}{c}\text { Cohesive } \\
\text { Force } \\
\boldsymbol{\sigma}_{\mathbf{1}} / \mathbf{M P a}\end{array}$ & $\begin{array}{c}\text { Water } \\
\text { Absorption, } \\
\boldsymbol{\eta} / \mathbf{\%}\end{array}$ & $\begin{array}{c}\text { Weight, } \\
\mathbf{m} \mathbf{2} / \mathbf{g}\end{array}$ & $\begin{array}{c}\text { Cohesive } \\
\text { Force } \\
\boldsymbol{\sigma}_{\mathbf{2}} / \mathbf{M P a}\end{array}$ \\
\hline $\mathrm{FPU}-0.5$ & 95.3 & 57.3724 & 12.61 & 2.52 & 58.8182 & 10.44 \\
$\mathrm{Al}_{2} \mathrm{O}_{3}-\mathrm{FPU}(1)$ & 104.2 & 57.8927 & 11.23 & 1.82 & 58.9463 & 10.31 \\
$\mathrm{Al}_{2} \mathrm{O}_{3}-\mathrm{FPU}(2)$ & 117.7 & 59.4325 & 10.85 & 1.46 & 60.3002 & 10.79 \\
$\mathrm{Al}_{2} \mathrm{O}_{3}-\mathrm{FPU}(3)$ & 122.8 & 58.4293 & 9.73 & 1.08 & 59.0603 & 9.68 \\
$\mathrm{Al}_{2} \mathrm{O}_{3}-\mathrm{FPU}(4)$ & 123.1 & 58.7361 & 7.17 & 1.04 & 59.3470 & 7.13 \\
\hline
\end{tabular}

$\mathrm{m}_{1} / \sigma_{1}$ is the weight/cohesive force of fluorinated polyurethane before the water absorption test; $\mathrm{m}_{2} / \sigma_{2}$ is the weight/cohesive force of fluorinated polyurethane after the water absorption test; $\eta=\left(m_{2}-m_{1}\right) / m_{1} \times 100 \%$.

\subsection{Analysis of Cavitation Wear Resistance of Coating}

The variation of the friction coefficient of FPU-0.5 was relatively large, ranging from 0.38 to 0.45 . The fluctuation range of friction coefficient of $\mathrm{Al}_{2} \mathrm{O}_{3}-\mathrm{FPU}(4)$ was small and stable, ranging from 0.65 to 0.68 . The amount of alumina increased slightly, and the friction coefficient of the coating increased gradually. The reason for this is that the alumina protrusion on the surface of the coating increases with the increase of the content. According to the data in Table 2, the actual cavitation amount $\mathrm{C}$ of the coating is less than the cavitation guarantee amount $C_{n}\left(C<C_{n}=2.4 \times 10^{-3} \mathrm{~kg}\right)$ converted to the line time, which is the standard for the material cavitation guarantee. In addition, with the increase of alumina content, the amount of cavitation of the coating is also reduced from $2.3755 \times 10^{-3} \mathrm{~kg}$ of FPU- 0.5 to $0.9035 \times 10^{-3} \mathrm{~kg}$ of $\mathrm{Al}_{2} \mathrm{O}_{3}$-FPU (4), and the anti-wear ability is increased by $61.9 \%$ compared with FPU-0.5. The erosion resistance performance is significantly improved. The coefficient of friction of the coating increases, and the amount of cavitation wear decreases. The anomaly of the coating is due to the nano-alumina particles. The addition of nano-alumina increases the surface roughness of the coating and increases the friction coefficient. However, due to the higher hardness, alumina can better resist the impact of abrasive particles and transfer the impact energy to the polyurethane matrix. The coating achieves the effect of rigidity and flexibility, and the overall wear resistance is stronger.

Table 2. The data of abrasive resistance experiments.

\begin{tabular}{ccccc}
\hline Sample & $\begin{array}{c}\text { Friction } \\
\text { Coefficient/ } \mu\end{array}$ & Weight, $\mathbf{m}_{\mathbf{1}} / \mathbf{g}$ & Weight, $\mathbf{m}_{\mathbf{2}} / \mathbf{g}$ & $\begin{array}{c}\text { Cavitation } \\
\text { Erosion, } \mathbf{C} / \mathbf{g}\end{array}$ \\
\hline FPU-0.5 & $0.38-0.45$ & 184.7388 & 182.3633 & 2.3755 \\
$\mathrm{Al}_{2} \mathrm{O}_{3}$-FPU (1) & $0.52-0.58$ & 183.2513 & 182.0060 & 1.2453 \\
$\mathrm{Al}_{2} \mathrm{O}_{3}$-FPU (2) & $0.58-0.64$ & 183.3752 & 182.2909 & 1.0843 \\
$\mathrm{Al}_{2} \mathrm{O}_{3}$-FPU (3) & $0.61-0.66$ & 184.4328 & 183.5015 & 0.9313 \\
$\mathrm{Al}_{2} \mathrm{O}_{3}$-FPU (4) & $0.65-0.68$ & 184.3437 & 183.4402 & 0.9035 \\
\hline
\end{tabular}

$\mathrm{m}_{1} / \mathrm{m}_{2}$ is the weight of samples before/after the water absorption test; $\mathrm{C}=\mathrm{m}_{1}-\mathrm{m}_{2}$.

In order to further investigate the internal structural changes of the coating during wear, DSC was used for testing. Figure 4 shows the DSC curves of FPU-0.5, and elongations of 0\%, 10\%, 30\%, and $70 \%$ are shown in Table 3. The glass transition temperatures of NDI+EDA, NDI +BDO, PBA-2000, and PTMG-3000 were compared as a reference. 


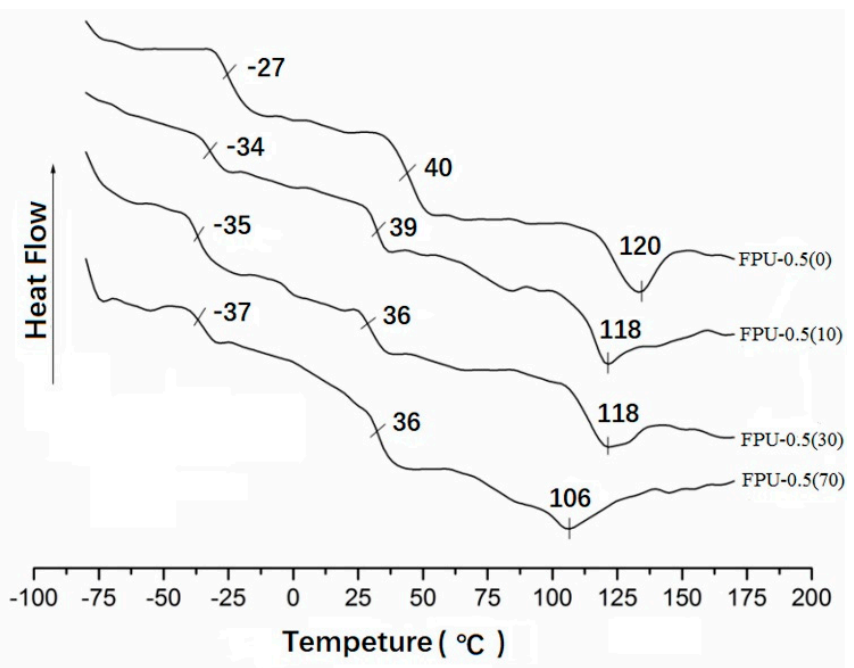

Figure 4. Differential scanning calorimetry (DSC) curves of different elongation FPU-0.5.

Table 3. Results of DSC scanning of polyurethane elastomers with different elongation FPU-0.5.

\begin{tabular}{cccccccc}
\hline Sample & $\begin{array}{c}\text { Soft } \\
\text { Segment } \\
\text { Phase }\end{array}$ & $\begin{array}{c}\text { Hard } \\
\text { Segment } \\
\text { Phase }\end{array}$ & $\begin{array}{c}\text { PU Melting } \\
\text { Temperature }\end{array}$ & $\begin{array}{c}\text { Soft Segment Structural } \\
\text { Unit }\end{array}$ & $\begin{array}{c}\text { Hard Segment } \\
\text { Structural Unit }\end{array}$ \\
\hline $\mathrm{T} /{ }^{\circ} \mathrm{C}$ & $\mathrm{Tg}(\mathrm{SS})$ & $\mathrm{Tg}(\mathrm{HS})$ & $\mathrm{Ta}$ & PBA2000 & PTMG3000 & NDI+EDA & NDI+BDO \\
\hline FPU-0.5(0) & -27 & 40 & 120 & & & & 73 \\
FPU-0.5(10) & -34 & 39 & 118 & -63 & -65 & 73 & 74 \\
FPU-0.5(30) & -35 & 36 & 118 & & & & \\
FPU-0.5(70) & -37 & 36 & 106 & & & \\
\hline
\end{tabular}

Figure 4 shows the DSC curves of FPU-0.5 under different stresses. The temperature range of $-27^{\circ} \mathrm{C}$ to $-37^{\circ} \mathrm{C}$ is the glass transition temperature $\left(\mathrm{Tg}_{(\mathrm{SS})}\right)$ of the polyester-polyether soft segment phase, the temperature range of $32{ }^{\circ} \mathrm{C}-39^{\circ} \mathrm{C}$ is the glass transition temperature of the hard segment phase $\left(\operatorname{Tg}_{(\mathrm{HS})}\right)$, and the extreme turning point of the hard segment crystalline melting temperature (Tm) appears in the temperature range of $105^{\circ} \mathrm{C}-128^{\circ} \mathrm{C}$.

It can be seen from Figure 5 that the glass transition of soft and hard segment of FPU with nano alumina increased, which may have been caused by the introduction of nano alumina. Since the nano-alumina has a strong polarity, when it was introduced into the polyurethane, a large number of hydrogen bonds formed between the soft and hard segments, and the force between the soft and hard segments increased. The degree of microphase separation in the soft and hard sections became smaller, so the glass transition temperature increased.

With the increase of external force, the $\mathrm{Tg}_{(\mathrm{SS})}$ and the $\mathrm{Tg}_{(\mathrm{HS})}$ of the polyurethane coating and hard segment crystallization temperature Tm of the polyurethane coating decreased. The glass transition temperature of the soft segment of FPU-0.5 exceeded those of the reference compounds, even at the highest external force. It is reported that the hardness of the soft segment phase is higher, the anti-friction performance is better, the glass transition temperature of the hard segment phase is lower, and the hard segment phase is more resistant to impact [31].

For the Tg in the block copolymer, it can be calculated by the Fox equation [32], as follows:

$$
\begin{gathered}
\frac{1}{\mathrm{Tg}}=\frac{\mathrm{W}_{1}}{\mathrm{Tg}_{1}}+\frac{\mathrm{W}_{2}}{\mathrm{Tg}_{2}} \\
\frac{1}{\mathrm{Tg}_{\mathrm{SS}}}=\frac{\mathrm{W}_{\mathrm{SS}}}{\mathrm{Tg}_{1}}+\frac{\mathrm{W}_{\mathrm{SS}}}{\mathrm{Tg}_{2}}+\frac{\mathrm{W}_{\mathrm{HS}}}{\mathrm{Tg}_{3}}+\frac{\mathrm{W}_{\mathrm{HS}}}{\mathrm{Tg}_{4}}
\end{gathered}
$$




$$
\frac{1}{\mathrm{Tg}_{\mathrm{HS}}}=\frac{\mathrm{W}_{\mathrm{SS}}}{\mathrm{Tg}_{1}}+\frac{\mathrm{W}_{\mathrm{SS}}}{\mathrm{Tg}_{2}}+\frac{\mathrm{W}_{\mathrm{HS}}}{\mathrm{Tg}_{3}}+\frac{\mathrm{W}_{\mathrm{HS}}}{\mathrm{Tg}_{4}}
$$

where $\mathrm{Tg}$ is the glass transition temperature $\mathrm{Tg}_{(\mathrm{HS})}$ of the hard segment phase or the glass transition temperature $T g_{(S S)}$ of the soft segment phase under different stresses. $W_{1}$ and $W_{2}$ are, respectively, the mass fraction of the structural units 1, 2 participating in the copolymer in the phase $\left(W_{1}+W_{2}=1\right)$; $\mathrm{Tg}_{1}, \mathrm{Tg}_{2}$ is the crystallization transition temperatures of structural units 1, 2. According to equations (6) and (7), the $\mathrm{Tg}_{(\mathrm{SS})}$ and $\mathrm{Tg}_{(\mathrm{HS})}$ of the soft and hard segments, and the $\mathrm{Tg}$ of the model compound, the microphase separation of the block polyurethane can be calculated as the soft segment unit in the soft and hard segment phase [33]. The mass fractions of the hard segment units are represented by $\mathrm{W}_{\mathrm{SS}}$ and $\mathrm{W}_{\mathrm{HS}}$; the results are shown in Table 4 .

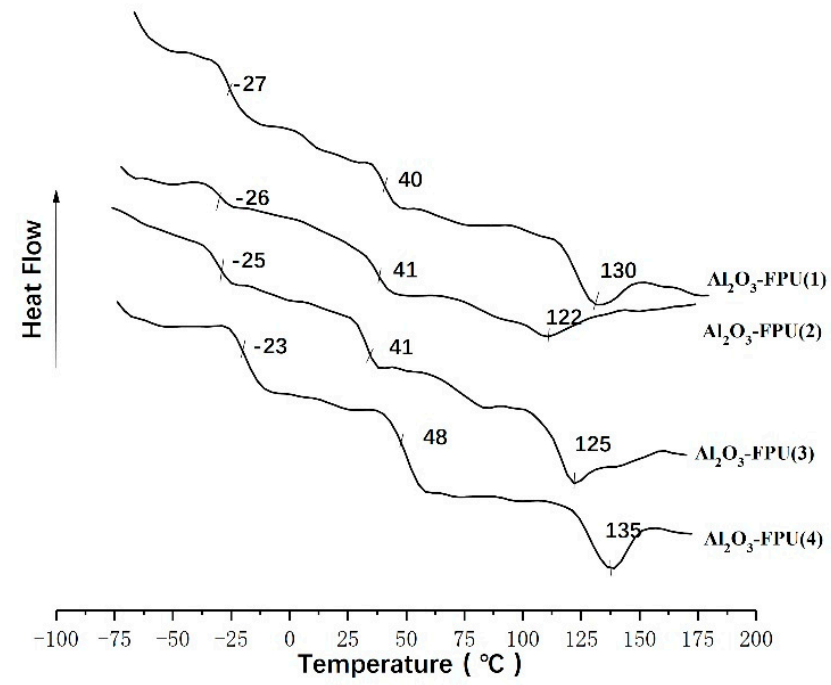

Figure 5. DSC curves of different nano alumina content coatings.

Table 4. Content of structural elements of soft and hard segments in soft and hard regions.

\begin{tabular}{ccccc}
\hline \multirow{2}{*}{ Sample } & \multicolumn{2}{c}{ Hard Phase Region } & \multicolumn{2}{c}{ Soft Phase Region } \\
\cline { 2 - 5 } & $\mathbf{W}_{\text {HS }}$ \% & $\mathbf{W}_{\text {SS }} \%$ & $\mathbf{W}_{\text {HS }} \%$ & $\mathbf{W}_{\text {SS }} \%$ \\
\hline FPU-0.5(0) & 79 & 21 & 22 & 78 \\
FPU-0.5(10) & 82 & 18 & 21 & 79 \\
FPU-0.5(30) & 84 & 16 & 19 & 81 \\
FPU-0.5(70) & 88 & 12 & 17 & 83 \\
\hline
\end{tabular}

As the external force of FPU-0.5 increases, the soft fraction structural unit mass fraction $\mathrm{W}_{\mathrm{SS}}$ decreased from $21 \%$ to $12 \%$ in the hard segment phase. Additionally, the hard segment unit mass fraction $\mathrm{W}_{\mathrm{HS}}$ also dropped from $22 \%$ to $17 \%$ in the soft segment phase of polyurethane. The reason for this change is that the $\mathrm{C}-\mathrm{N}$ bond between the soft and hard segments breaks in the process of increasing external pressure, resulting in a decrease in the mixed density of the soft and hard segments. When the elongation was small, the $\mathrm{C}-\mathrm{N}$ bond was not broken, but the hydrogen bond and the subvalent bond may have broken at this moment, improving the degree of microphase separation. At the same time, the cross-linking action of the soft and hard segments was ensured, and the mechanical dynamic synergistic effect between the microscopic phases improved.

It can be seen in Figure 6, under the repeated action of wear particles, micro jets, and shock waves, that the macroscopic macromolecular chains are destroyed, and the partially broken flexible segments are separated from the matrix, forming furrows, holes, and other damage on the surface of the coating. The glassy hard segment remains on the surface of the coating, and, due to its high hardness and modulus, the coating surface is prevented from expanding to a greater extent on the 
coating. The hard segment microdomains increase the intermolecular cohesive energy due to the introduction of higher polarity fluorine groups, thereby increasing the tensile strength and elastic modulus of the hard segment microdomains. When the coating was subjected to erosion, the hard segment on the surface of the coating resisted the wear of the abrasive particles, and the impact energy was transmitted inward through the hard segment to the soft segment of the elastic state inside the coating. The soft segment molecular chain provides buffering and absorption of impact energy, and overall improves the cavitation wear resistance of the coating [34-36].

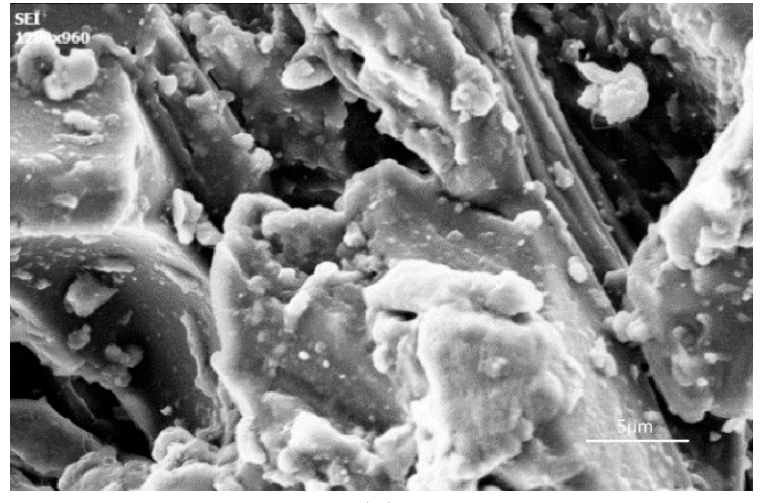

(a)

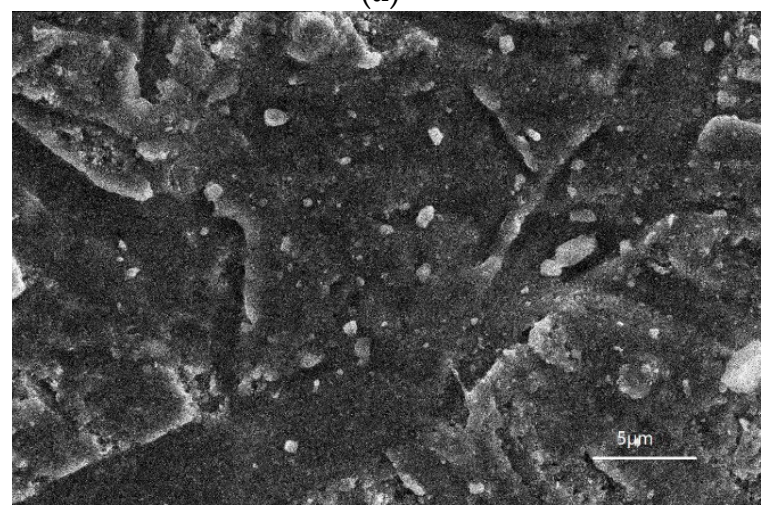

(c)

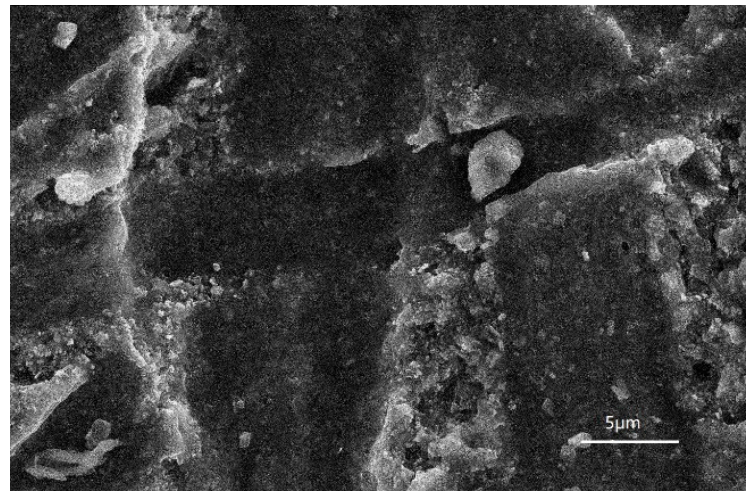

(b)

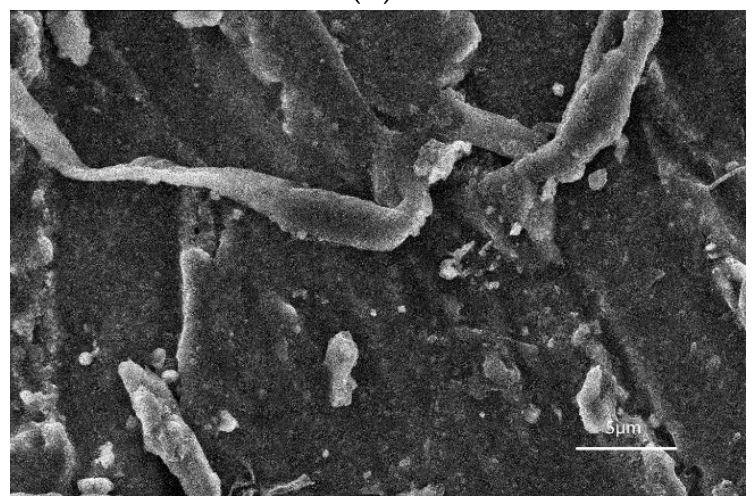

(d)

Figure 6. Surface morphology of coatings after wear: (a) $\mathrm{Al}_{2} \mathrm{O}_{3}-\mathrm{FPU}(1)$, (b) $\mathrm{Al}_{2} \mathrm{O}_{3}-\mathrm{FPU}(2)$, (c) $\mathrm{Al}_{2} \mathrm{O}_{3}-\mathrm{FPU}(3)$, and (d) $\mathrm{Al}_{2} \mathrm{O}_{3}-\mathrm{FPU}(4)$.

\section{Conclusions}

In this paper, fluorine is successfully introduced by reacting perfluorooctylethyl alcohol (TEOH-8) with diphenylmethane diisocyanate (MDI). Attenuated total reflection-Fourier transform infrared spectroscopy (ATR-FTIR) analysis shows that the FPU synthesized in this experiment does not contain hydrophilic $-\mathrm{CH}_{2} \mathrm{OH}$ groups. Within the experimental range, the water resistance results indicate that the water resistance of the coating increases as the content of nano-alumina increases. The cavitation wear test shows that the actual cavitation amount $C$ of the FPU coating is $0.9035 \times 10^{-3} \mathrm{~kg}$, which is less than the cavitation guarantee amount $C_{n}$ according to the running time, and the anti-wear ability is improved by $61.9 \%$. The observation of the coating shows that the high hardness alumina particles on the surface of the coating and the CF chain with high surface bond energy make the coating have high strength and excellent wear resistance and water resistance, which can prevent wear from continuing to penetrate the coating, and the life of the coating is improved. The results show that the alumina-modified fluorinated polyurethane composite coating is significantly improved in terms of water resistance and wear resistance. 
Author Contributions: Conceptualization, R.Z. and W.W.; methodology, W.W.; validation, W.W., R.Z., and W.T.; formal analysis, W.W.; investigation, C.W.; resources, R.Z. and J.H.; data curation, W.T.; writing一original draft preparation, W.W.; writing-review and editing, W.W. and M.I.H.; supervision, R.Z.; project administration, R.Z. and J.H.

Funding: This research was funded by Henan Province Innovative Technology Team (C20150017), Key Laboratory of Zhengzhou City (Zheng Technology [2014]3-10), Henan Province Engineering Technology Research Center (Yuke2016-221-High-tech35), Third Batch of Zhihui Zhengzhou 1125.Jucai plan-innovation shortage of talents (ZhengZheng [2018]-45-15).

Conflicts of Interest: The authors declare no conflict of interest.

\section{References}

1. Gu, S.-X.; Jiang, R.-Q.; Zhang, Y.-Y.; Yang, G. Abrasion and prevention of turbine. Des. Water Resour. Hydroelectr. Eng. 2011, 30, 39-43.

2. Trezza, M.A.; Scian, A.N. Materials issues in renewable energy power generation. Fuel Energy Abstr. 2002, 43, 53-54.

3. Sun, Y.; Bell, T. Dry sliding wear resistance of low temperature plasma carburised austenitic stainless steel. Wear 2002, 253, 689-693. [CrossRef]

4. $\mathrm{Qu}, \mathrm{Y}$. The present situation and developing direction of heavy-duty coating at home and abroad. Chem. Ind. 2013, 31, 25-34.

5. Bae, J.; Chung, K.-H. Accelerated wear testing of polyurethane hydraulic seal. Polym. Test. 2017, 63, 110-117. [CrossRef]

6. Mirhosseini, S.S.; Shoja Razavi, R.; Taheran, M.; Barekat, M. Wear behavior of polyurethane/carbon black coatings on 6061 aluminum alloy substrates. Prog. Org. Coat. 2016, 97, 37-43. [CrossRef]

7. Wu, Z.; Guo, Z.; Yuan, C. Influence of polyethylene wax on wear resistance for polyurethane composite material under low speed water-lubricated conditions. Wear 2019, 426-427, 1008-1017. [CrossRef]

8. Xiao, S.; Sue, H.-J. Effect of molecular weight on scratch and abrasive wear behaviors of thermoplastic polyurethane elastomers. Polymer 2019, 169, 124-130. [CrossRef]

9. Cheng, F.T.; Shi, P.; Man, H.C. Cavitation erosion resistance of heat-treated NiTi. Mater. Sci. Eng. A 2003, 339, 312-317. [CrossRef]

10. Hou, L.; Peck, Y.; Wang, X.; Wang, D. Surface patterning and modification of polyurethane biomaterials using silsesquioxane-gelatin additives for improved endothelial affinity. Sci. China Chem. 2014, 57, 596-604. [CrossRef]

11. Joshi, M.; Adak, B.; Butola, B.S. Polyurethane nanocomposite based gas barrier films, membranes and coatings: A review on synthesis, characterization and potential applications. Prog. Mater. Sci. 2018, 97, $230-282$. [CrossRef]

12. Liu, C.; Xiang, B.; Liu, Y.; Huang, Q.; Yang, Y.; Chen, S.; Bai, G.; An, Q.; Cao, J.; Zheng, S.; et al. Synthesis of aqueous and hydroxy-terminated polyurethanes: Impacts of formulation parameters by orthogonal matrix design. Prog. Org. Coat. 2016, 90, 1-9. [CrossRef]

13. Moholkar, V.S.; Kumar, P.S.; Pandit, A.B. Hydrodynamic cavitation for sonochemical effects. Ultrason. Sonochem. 2001, 6, 53-65. [CrossRef]

14. Li, Z.; Shen, Y.; Zheng, C.; Gu, X.; Li, J.; Gao, Y. Preparation and Properties of Fluorosilicone Polyether Polyurethane Underwater Acoustically Transparent Encapsulant. Mater. Today Commun. 2019, 19, 402-406. [CrossRef]

15. Zhou, Y.; Liu, C.; Gao, J.; Chen, Y.; Yu, F.; Chen, M.; Zhang, H. A novel hydrophobic coating film of water-borne fluoro-silicon polyacrylate polyurethane with properties governed by surface self-segregation. Prog. Org. Coat. 2019, 134, 134-144. [CrossRef]

16. Chen, L.; Hayashi, M.; Takasu, A. Hydrophobicity enhancement of polyurethanes by attaching fluorinated end blocks via ATRP and correlation between surface properties and self-assembly nature. Polymer 2019, 172, 312-321. [CrossRef]

17. Li, B.; Li, S.-M.; Liu, J.-H.; Yu, M. The heat resistance of a polyurethane coating filled with modified nano- $\mathrm{CaCO}_{3}$. Appl. Surf. Sci. 2014, 315, 241-246. [CrossRef]

18. Song, H.-J.; Zhang, Z.-Z. Investigation of the tribological properties of polyfluo wax/polyurethane composite coating filled with nano-SiC or nano-ZrO2. Mater. Sci. Eng. A 2006, 426, 59-65. [CrossRef] 
19. Sun, D.; Miao, X.; Zhang, K.; Kim, H.; Yuan, Y. Triazole-forming waterborne polyurethane composites fabricated with silane coupling agent functionalized nano-silica. J. Colloid Interface Sci. 2011, 361, 483-490. [CrossRef]

20. Li, R.; Xiao, F.; Amirkhanian, S.; You, Z.; Huang, J. Developments of nano materials and technologies on asphalt materials-A review. Constr. Build. Mater. 2017, 143, 633-648. [CrossRef]

21. Zhou, R.; Lu, D.H.; Jiang, Y.H.; Li, Q.N. Mechanical properties and erosion wear resistance of polyurethane matrix composites. Wear 2005, 259, 676-683. [CrossRef]

22. Chen, Y.F.; Chu, H.Y.; Zhang, Q.Y.; Teng, C.J.; Tan, J.Y. Preparation and Mechanical Properties of $\mathrm{Al}_{2} \mathrm{O}_{3}$ Modified MDI Polyurethane Elastomer. J. Harbin Univ. Sci. Technol. 2016, 21, 117-122.

23. Zhang, M.; Han, J.W.; Weng, Y.X.; Li, C.T. Preparation and Corrosion Resistance of High Filling Hydrophobic $\mathrm{Al}_{2} \mathrm{O}_{3}$ /TPU Anti-corrosion Peelable Film. Polym. Mater. Sci. Eng. 2019, 35, 143-149. [CrossRef] [PubMed]

24. Manohar, N.; Jayaramudu, J.; Suchismita, S.; Rajkumar, K.; Babul Reddy, A.; Sadiku, E.R.; Priti, R.; Maurya, D.J. A unique application of the second order derivative of FTIR-ATR spectra for compositional analyses of natural rubber and polychloroprene rubber and their blends. Polym. Test. 2017, 62, 447-453. [CrossRef]

25. Wang, X.-C.; Zhang, F.-F.; Qing, T.-T. Study on adsorption characteristics and mechanism of hyperbranched collagen fibers adsorbent on Cr (VI). J. Chem. 2012, 70, 2536-2542.

26. Zhang, R.-Z.; Ren, Y.-Y.; Yan, D.-K.; Guo, P.-Y.; Li, L.-J. Synthesis of hydrophobic fluorinated polyurethanes and their properties of resistance to cavitation and wear. Prog. Org. Coat. 2017, 104, 11-19. [CrossRef]

27. Jiang, Y.; Shen, Y.; Wu, P.-Y. Application of ATR-FTIR spectroscopy in polymer film study. Prog. Chem. 2007, 19, 173-185.

28. Jiang, Z.; Yuan, K.-J.; Li, S.-F.; Zhou, Y.-J.C. Study on FTIR Spectrum and Thermal Analysis of Polyurethane. Spectrosc. Spectr. Anal. 2006, 4, 624-628.

29. Dai, J.B.; Zhang, X.Y.; Chao, J.; Bai, C.Y. A new core-shell type fluorinated acrylic and siliconated polyurethane hybrid emulsion. J. Coat. Technol. Res. 2007, 4, 283-288. [CrossRef]

30. Luo, X.-D.; Xu, J.; Tang, W.-H.; Dai, X.-Y.; Zhang, X.-L. Synthesis and characterization of fluoro-modified polyurethane. Polym. Bull. 2001, 115, 57-62.

31. El-Shekeil, Y.A.; Sapuan, S.M.; Abdan, K.; Zainudin, E.S. Influence of fiber content on the mechanical and thermal properties of Kenaf fiber reinforced thermoplastic polyurethane composites. Mater. Des. 2012, 40, 299-303. [CrossRef]

32. Yang, C.; Jiang, J.-Z. Preparation and properties of waterborne polyurethane with hydrophobic branched chain. Paint. Coat. Ind. 2013, 43,1-4.

33. Yesudass Sebastin, A.; Mohanty, S.; Nayak, S.K. Synthesis and characterization of eco-friendly siloxane-semifluorinated polyurethane coatings for underwater application. J. Appl. Polym. Sci. 2019, 136, 291-300. [CrossRef]

34. Xu, C.; Lei, O.; Cai, Z.; Ren, Y.; Lu, S.; Shi, W. Effects of polyaminosiloxane on the structure and properties of modified waterborne polyurethane. J. Appl. Polym. Sci. 2019, 136, 47226. [CrossRef]

35. Yin, H.; Dai, Q.; Hao, X.; Huang, W.; Wang, X. Preparation and tribological properties of graphene oxide doped alumina composite coatings. Surf. Coat. Technol. 2018, 352, 411-419. [CrossRef]

36. Yu, M.; Cui, Z.; Ge, F.; Tian, H.; Wang, X. Simple spray deposition of a hot water-repellent and oil-water separating superhydrophobic organic-inorganic hybrid coatings via methylsiloxane modification of hydrophilic nano-alumina. Prog. Org. Coat. 2018, 125, 15-22. [CrossRef]

(C) 2019 by the authors. Licensee MDPI, Basel, Switzerland. This article is an open access article distributed under the terms and conditions of the Creative Commons Attribution (CC BY) license (http://creativecommons.org/licenses/by/4.0/). 